\title{
Collectivism and Individualism in Modern Russia
}

\author{
Vladimir D. Mamontov ${ }^{1}$, Tatiana M. Kozhevnikova ${ }^{1} \&$ Yana Y. Radyukova ${ }^{1}$ \\ ${ }^{1}$ Tambov State University named after GR Derzhavin, Tambov, Russia \\ Correspondence: Tatiana M. Kozhevnikova, Tambov State University named after G. R. Derzhavin, Tambov, \\ Komsomolskaya square, 5, Tambov, Russia. Tel: 7-4752-72-3434. E-mail: Tatiana-kozhevnikova@mail.ru
}

Received: August 26, 2014 Accepted: September 18, 2014 Online Published: November 14, 2014

doi:10.5539/ass.v10n23p199

URL: http://dx.doi.org/10.5539/ass.v10n23p199

\begin{abstract}
Our society is breaking certain dogmas and is fascinated by others, destroys the old idols and worship the new ones. Economic and political conflicts would not be perceived so painful, if we did not lose the eternal spiritual objectives. Former social ideal, collectivism, recede into the background, replaced by the new individualism, supposedly is bound up in the market economy. Meanwhile, even in the West, individualism as a principle of social life and behavior have been strongly criticized for a long time.The categories of "collectivism" and "individualism" can be the methodological research tools and can provide the opportunity to separate the vital changes from nihilism. This article analyzes the collectivist and individualist principles in business activities in Russia, defining the modern of the Russian society. It gives a retrospective analysis of the issue, studies the causes of deviant worldview patterns of social organization in relation to the original Russian, including the Soviet mentality.
\end{abstract}

Keywords: collegiality, collectivism, individualism, liberalism, labor, government

\section{Introduction}

Many researchers consider collectivist and individualist orientations as key oppositions mutually exclusive. Over a long period of time, the history moves between the two poles, on the one hand it is a collectivist society, on the other -an individualistic one. Collectivist orientations are originated from the values of the peasant community and labor cooperatives, mutual aid, labor democracy, local self-government, as well as in the power of ideology of the collectivism of the socialist era. In modern Russian conditions we began talking about the individualistic orientations at work more often, which is expressed in the self-realization of the person ambition, freedom of choice. However, in recent studies researchers admit the fact that collectivism and individualism, being evalectic antinomies, are integral elements of the national mentality. You cannot deny the fact that a man has both the collectivist principles and the individualism. The reason is that the person is unable to live apart from society and to be fully independent. The human person, unlike animals, cannot long exist without the society and without the threat of being degraded.

\section{Description of the Subject}

The division of society into types has a century of history. Any notion of the social control takes the certain specificity of the corresponding society, due to which the organizational process is represented as the corresponding to the society life. Historically, Russia has been embodied in collectivist forms of life of the Russian people, which ensures the integrity of the system and the stability of the Russian society. In contrast, Western society lives according to the individual development and its basic standards - equality and freedom. The transition from one type of society to another type is a difficult step in the development of this society, there is a reassessment of values, lifestyle change, a change of mentality. The article is devoted to the study of the phenomenon of collectivism as a historically specific phenomenon of Russian development and the adverse Western individualism, which is so popular nowadays.

\section{Methods and Techniques}

The theoretical and methodological basis of research are the fundamental concepts and hypotheses related to the forms of economic activity and based on the principles of collectivism and individualism, which are presented in classic and contemporary works of Russian and foreign scientists. 
The methodological basis of the study is the dialectical method of cognition, revealing the contradictory as the basis of the motion and the development of objective reality. In the development of theoretical propositions of the study within the framework of the systematic approach to the study of the concept of individualism and collectivism the methods of structural and functional, comparative analysis, the methods of the scientific abstraction, induction and deduction have been applied.

The formation of a new theoretical approach to the consideration of such categories as collectivism and individualism required the use of the ontological approach to this phenomenon of objective reality, which was embodied in the subjective activity of economic entities, which have power.

The research on the influence of some forms of economic activity on the development trends of the national economy has been conducted by the implementation of the general research methods: historical and logical method, systematic and functional analysis and synthesis, and others. In the study we used the wide range of the epistemological tools, such as: structural method, the method of hypothesis and deduction, historical genetic and categorical methods, as well as the methods of economic-mathematical modeling and economic and statistical research.

In the work has been also used the method of cross-country comparisons (with the elements of regression analysis), which allows to identify and assess trends in the development of national economies.

The accuracy of the results of the study has been provided by the methodological validity of assumptions, logic, consistency study, a representative experimental array sample and assessment of the state of the mass experience, the results of the experimental work.

The information and empirical basis of the study is based on the materials of international and Russian scientific and practical conferences devoted to the problems of finding new forms of economic activity, the development of a new model of social development; articles in periodicals and scientific and practical publications, information, analytical and methodological materials, expert assessments, as well as materials on the Internet.

\section{Results}

First the concept of collectivism was described by Aristotle, saying about equality between the citizens and the state, thus revealing the basic principle of a collectivist society, "Who believes the happy life of one man in wealth, he acknowledges happiness of the whole state, if it is rich." Aristotle says about the priority of the state, as an integrated collective reality, in relation to private, individual: "It is necessary that the whole takes priority ofthe part, the state exists by nature and by nature it is prior to each person. "Philosopher also explains the standards of naturalness in the principle of collectivism, namely the perfection of social relations and moral virtues. According to the statements of Aristotle, the benefit of society and the individual is the consequence of the virtuous society represented by all its citizens. In Russian, the term "collectivism" has some synonyms "community" and, in a higher sense, "collegiality."

According to N.M. Churilov, collegiality is a set of assumptions about the universal connection of phenomena of the human world of the Slavs, its spiritual unity, collectivist type of economy, about the forefront that puts together the Russian people. Characteristic Russian society standard of naturalness is reflected in one of the main Orthodox commandments - love for one's neighbors. Conciliar God-manhood, which is opposed to "the hated separateness of the world" (in the words of St. Sergius of Radonezh), according to the prominent Russian philosophers, is the perfect state of society, which overcomes any discord and enmity between people. From the perspective of the theory of catholicity the Russian society appears as a conciliar unity of the whole "world", and the concept of catholicity is a reflection of the principal ideal of socio-religious outlook of the Russian people (Grigorenko, 2006).

Fundamental notions of collegiality, rising to the standard of perfection of social relations and expressing the essence of the principle of collectivism, are the concepts of unanimity, oneness and consensus wittedness. Their meaning is revealed in the dialectics of the unity and the many, when one assumes a lot, but a lot - a single. It is necessary not to make a mistake - mindedness is not a uniformity, and there is a desire to come to a common solution, that is, to the consistency of decisions between themselves. Thus, the concept of unanimity, oneness and consensus wittedness are the extension of the Aristotelian tradition of researching the foundations of the life of a collectivist society. (Kulisher, 2004)

Collectivist society is characterized by collectivist standards of naturalness - objective laws of social development, moral virtues (in other words, the theory of catholicity implies the principle of universal communication of events as the idea of harmonization of social norms, law, morality, religion). 
Western society, criticizing the community and collectivism as obstacles of the development of a free person, lives in accordance with individualistic sociality, primary standards of which are equality and freedom. These concepts are reflected in the theory of liberalism, one of its founders was Thomas Jefferson. The liberal conception of social control proclaims the inviolability of human rights and individual freedoms in favor of minimizing government interference in people's lives. Rights and freedoms of an every person are determined by the highest value and are the legal basis of the social and economic order. The liberal conception of social control is aimed at achieving a certain goal by the management entity, so we can select another important standard - consumption. This concept of social control involves creating optimal conditions for the realization of consumer interests of the society.

The form of practical realization of the liberal conception of the social control is democracy as a political system, the essence of which is revealed in the term "freedom." The basis of democracy is the principles of freedom and equality of all before law.

Individualistic type of society corresponds to individualistic standards of naturalness, i.e. natural law, the natural state, the establishment of an appropriate system of laws. Let us conduct a retrospective analysis of this issue.

Russian civilization is one of the oldest world cultural civilizations. Relying on the core values, the Russian people managed to create the greatest country in world history that was able to combine harmoniously many different nations, to develop the great culture, literature, and art as spiritual wealth of all the mankind. The main features of the Russian civilization are the predominance of spiritual and moral priority of life over material, its focus not on consumer expansion but maintenance of economic self-sufficiency, the development of distinctive forms of self-employment in such forms as the community and the cooperative. National traditions of the country are not in conflict with its economic practices that contributed to the economic success of the state. (Eucken, 1996).

Russian communal type of economy was based on traditional Christian values of rural communities and the farm, the collectivism, the mutual aid, the local government, the labor democracy. Effective work was motivated not only by the financial incentives but the moral ones. (Berdyaev, 1990).

First denial of original foundations of Russian economy was observed in the XV-XVI centuries, amplification was occurred in the XVII-XVIII centuries, and the threatening character - in XIX century. The denial of economic foundations of life was demonstrated by the higher parts of the ruling class and the nobility, preferring the borrowed, mainly from Western Europe, forms, and ideas. Serious chock to the national economy was the consolidation model of serfdom, which was not characteristic for the Russian Institute.

Imposition of Western economic forms was supplanting the Russian form of management, many well-known economists of the nineteenth century simply ignored the Russian economic thought. For example, the finance ministers of E.F. Kankrin and N. H. Bunge, economists V.V. Bervi (Flerovsky), N.I. Sieber et al. were imposing both in practice and in the science the Western economic ideas, ignoring the millennial economic experience of the great country, and if they took it into account, then saw it as an inevitable evil on the way to the ultimate goal of ousting a distinctive Russian farming as a historical anachronism being irrelative.

In the $60-80$ s. XIX century in the Russian economy there was a sharp struggle of domestic and foreign economic patterns.

Westernized system of thought mostly of the ruling circles, as well as the intellectuals condemned to degradation and degeneration of Russian forms of management and labor, however, it was associated with the achieving the economic success. Despite the views of the educated population, the folk forms of economic activity continued to exist effectively, especially in agriculture, medium and small-scale industry. Moreover, it should be noted that during this period there was a synthesis of folk basics and advanced techniques and technology, which became the basis, in a sense, to the Russian economic miracle at the end of XIX - beginning of XX century comparable only to that of "Japanese economic miracle" after World War II. And this is not surprising, as both Russia and Japan were able to secure an unprecedented economic success by the synthesis of the advantages of traditional national culture and economic benefits associated with the implementation of the latest techniques and technology. Russian industry has shown the unprecedented growth rates, indices increased by 13 times in comparison with the pre-reform period. Economic growth rates were the highest in the world, and in some branches even huge - steel production increased by 2234 times, oil - in 1469, and coal - in 694, engineering products - 44 times, chemistry products - 48 times. At the end of XIX - and the beginning of XX century a radical re-equipment of industry was made. The share of production accumulation was $15-20 \%$ of national income, which was higher than in the United States. Only in 1885 - 1913 large corporate enterprises increased their funds by11.1 times. Average growth of productive assets was during 7,2\% per year at this period, that is 
again higher than in the United States. A symbol of economic prosperity of Russia of this period was the Great Siberian Railway, embodied all the previous economic achievements of the country.

It was one of the most daring and great economic projects of the time, embodied in life. Metal, rails, wagons, locomotives - all produced at Russian factories by Russian workers.

In agriculture, Russia ranked first in the production of crops, growing more than half in the world's production of rye, more than a quarter of wheat and oats, about two-fifths of barley, about a quarter of the potatoes. Russia was a major exporter of agricultural products, the first "breadbasket of Europe", which accounted for two-fifths of total world exports of peasant production.

At the beginning of XX Russia was the only country that is approaching self-sufficiency. It was independent of foreign import and export, due to the fact that it could fully provide all necessary goods and it consumed all that produced. High tariffs stimulated the domestic economy. Russia's share in global imports at the beginning of XX century was slightly more than $3 \%$ that was for the country with the population equal to a tenth of all the mankind, was negligible. For comparison, it should be noted that the majority of Western countries had a greater share of global imports, but with small population. Russia was economically independent from the rest of the world, the Western countries, on the other hand, they were dependent on its resources.

Russian economic blockade stopped at the initiative of the Western countries, starting from that moment the exploitation of Russian recourses. Concern was caused by the fact of unequal nature of the foreign trade when raw materials were bought at low prices. Unequal exchange of the products of labor between Russia and Western Europe was noted by many economists after the Russian Slavophiles. In 1887, a businessman and an economist V.A. Kokorev wrote about pumping resources of Russia to the West.

Westerners argued that the economic relations with Europe are the main source of Russian wealth. However, the facts told a different story. Benefit from this relationship was largely one-sided. For the period of $1886-1913$ a lot of extremely low priced goods mainly raw materials at 25.3 billion rubles were exported from Russia, and imported at very high prices of goods, many of which could be produced in Russia, at 18.7 billion rubles. As a result, the country lost at least $5-10$ billion rubles of people's labor. "Rapprochement with Europe -is a bit exaggerated as pointed M.O. Menshikov pointed out - ravaged Russia, made it forget to meet their needs, deprived of economic independence. However, half a century ago in the village the sugar valued almost worth its weight in silver, but the honey was for nothing. Now oranges are almost cheaper than apples, but the strange thing is that apples are already more expensive than oranges. The most simple, once nearly worthless products in the village - mushrooms, berries, milk, butter, poultry, crayfish, nuts - were hardly accessible to people" (Platonov, 2008).

The rate of economic growth in Russia was ahead of Western countries, but the volume of industrial production in the country was still lagging behind the United States, Britain, France and Germany, ranking fifth in the world. Specialists, based on the analysis of industrial capacities and average annual growth rates of production, predicted by 1930, Russia's entry into one of the front line of the global economic development.

These results the country could be achieved through a special type of business, based on the collectivist forms, ensuring system integrity and stability of the Russian society. Seneca gave a good image of collectivism. He wrote: "Let us remember that we were born to live together. And our community is like a vault, which is strong because the stones do not give each other to fall down".

Team spirit in the external manifestations has always existed in Russia. So, apparently it manifested in 20-30 years, with "building a new society," even brighter - in acts of mass heroism in World War II. The history of this time is full of episodes of unparalleled sacrifice of people in the name of victory over fascism. Then the same external forms of collectivism were traditionally manifested in separate episodes of labor enthusiasm even in 60-70 years, up until the time that is now called "stagnation". Almost all official Soviet literature is written on stories that took place in real life, when people spared no effort, health, or even at the expense of their lives were committing labor achievements "for the benefit of the motherland". A man, for instance, could die to save a herd of horses from the fire or to save the collective farm harvest. And nothing could be further from the mind that horses or crop can be grown many times, and it is impossible to return the person. We cannot say that such actions of people were forced or they were obliged or forced to behave sacrificially, being threatened. (Kozhevnikova, 2012)

The Russian school of economic thought has always been characterized by the recognition of the primacy of common national economic approach over the activities and motivations of individuals, at least it was before the transition to a market economy. 
In the course of market reforms, Russia, remaining still a country with a predominance of working people became almost a "hegemon on individualism", ahead of all countries. People suddenly forgot about collectivism, and their energy was directed to the purpose of personal enrichment that led to fragmentation, the inability to create a stable coalition and use them to defend and implement the group, collective and national interests. During the period of transformation new generation grew up, matured in conditions of extreme social injustice in the wild environment of social stratification. It seemed that, in relative freedom the new generation had a lot of chances to organize itself and to make the country build a civil society. However, nothing of the sort happened. Even in moments of the greatest political freedoms 90s Soviet people were not able to create any mass political party and no union. All current parties and trade unions on the old tradition lowered wise heads. For comparison, in Germany, the German is a member of a dozen organizations, and it is considered the norm. Sociological studies of young Russian businessmen show extremely high level of individualism. Meanwhile, it should be emphasized that collectivism is widely developed in Japan with its system of lifetime employment, in China with a strong tradition of rural community relations and in some other countries.

In the modern economy of Russia we can see the increasing the role of institutions representing universals that define the structure of the rules of human behavior. By their nature, the rules are not personalized, they are associative, and therefore represent a kind of "economic imperative", collective organizing power. Entrepreneurs are cooperated in institutions (professional associations), consumer - in societies and cooperatives, workers and specialists into works councils in firms, etc. Collective interests, joint actions, operating on the principle of mutual checks and balances and incentives protect against excessive fragmentation and atomization, ensure the integrity of the economy. Collectivity, especially in industrial activity, has internally inherent normative content. Regulatory authority directs the actions of individuals on the road usually shaped behavior.

The degree of separation or connection of manufacturers with the deepening of the social division of labor, the development of productive forces and relations of production are changing. Associativity, co-operation combines with the isolation, individualization. Collective work does not deny individual appropriation. On the contrary, the latter is enriched, modified on the basis of collective labor, complexity in it of technical labor, organizational, industrial, social and economic ties. It may be one model in the fields of economy, acceptable for small and medium business (trade, catering, domestic services and city transport and communication), where the priority is individual private interests; and a very different model of large-scale enterprise with a high level of socialization, concentration of production and capital in knowledge-intensive and capital-intensive sectors (aeronautics, space technology, shipbuilding, transport machinery, nuclear power), where priority is interests that are associative up to countywide and national interests.

Considering the ratio of individualist and collectivist interests and the differences between private and public goods, we cannot do without mentioning the role of the state as the exponent of the defense of public interests. State adjustments in spontaneous market processes give the economy a social character, as protected and balanced the interests of all market participants regardless of their size and power. This is achieved through the creation of conditions for equal and fair competition in the suppression of monopoly and restriction unreasonable overproduction, dumping prices and other negative phenomena, leading to all sorts of economic and financial crises. Without an inclusive macro regulation of the modern state it is almost impossible the functioning of market economy ( Mamontov \& Kozhevnikova, 2013).

The task of the science is to research different options to combine individualism and collectivism in the specific conditions of economic activity. We can understand the modern mechanism of interaction of private and public interests only in their complex unity, not in opposition to their mechanical as mutually exclusive categories.

Judging by the actions of public authorities of modern Russia, their interaction with civil society, then there is a mutual desire to create a strong national government with the liberal-democratic values, developed market economic relations. Of course, this is a very complex issue, given the long Soviet past of the country, especially since there is a global trend to humanize the social and economic relations in the developed countries, which are designated in the second half of the twentieth century.

In different social and economic systems the focus is on the different socio-cultural values of social life: collectivism or individualism, asceticism or material prosperity, labor enthusiasm, heroism or personal creativity. In this case, the political system of a society determines what is valuable and what is not. Thus, the result of a complex reform of post-Soviet period was the transition of Russian society to the new political and socio-economic system with the new social ideology and values. This is evidenced, for example, the dramatic changes that have occurred in recent decades in Russia, first in labor law, and then, as a consequence, in the system of labor relations and labor values shared by society. Under the values of labor we understand common 
people's beliefs about the importance of their work as a whole, as well as its content and purpose. Identify several trends related to the formation of a new value system of labor.

Firstly, there was a transformation of the labor from the universal duty of an able-bodied citizen into his right. This is reflected primarily in the legalization of the status of the unemployed. An unemployment citizen is no longer perceived in society as antisocial or unlawful phenomenon. In the present conditions it is impossible to bring to responsibility a man who is not busy in socially beneficial labour activity. Moreover, many people of creative professions are considered self-employed and are considered one of the most successful people who are able to self-actualize, to reveal their personal potential.

Second, the Russians changed their minds about the prestige and the significance of specific types of work. Some kinds of occupations, related primarily to industrial agricultural production, have lost their appeal, antisocial groups of workers and peasants - their status position of the leading subjects of social and cultural dynamics of society. As a result, the value of the specific role of labor has lost the most important socio-cultural factor that unifies the society. Under the conditions, a professional structure, and non-class becomes more important for the stratification of society.

Third, motives of employment have undergone significant changes. A labor of love for the benefit of the whole society, donation of their personal interests for the benefit of the collective labor enthusiasm lost its role as the leading motive of work and factors of social development. Individual private interest is considered the main motive of productive activity. Modern labor ideology now welcomes the activities of the person in the name of increasing personal wealth, achieve personal prosperity. In these circumstances, the criterion of success of a man became its ability to provide a high level of personal consumption and the amount of accumulation of wealth.

Fourth, the status function of employment has been transformed. It is known that the status positions of different population groups are formed in the social structure and the system of social relations by certain labor employment. A person engaged in any kind of work, through self-awareness of its importance to society and the membership of a particular social group, identifies himself with the community and gets a sense of personal safety, psychological security as well as an opportunity to increase personal self-esteem. That is the employment, performing the status function is a source of human identity.

For example, a sense of labor identity, based on the attachment of the general population to the factory (industrial) production culture, is specific to industrial society. It is in such a society, the dismissal from work, the change of the status of the worker to the status of an unemployed becomes a real personal disaster, leading to the loss of labor identity. According to the theory of modernity of Manuel Castells in today's society, where everything is more and more widespread in an information technology, there is the transformation of the "space of places" into the "space of flows." In these circumstances, the feeling of labor identity begins to dominate based on attachment to the professional community. Such labor identity is not linked to a specific company, factory, or the workforce. It should be noted that there is an increase in the variety of forms of employment, to effectively implement social and labor potential of the population. This is due, on the one hand, to the legalization of private property rights and business, and on the other hand, to the development of scientific and technical progress, the expansion of information society that contribute to new forms of employment, non-attachment to the traditional workplace (Ritzer, 2002).

Meanwhile, in Russia during the years of structural reforms in the late XX century, there was an actual de-industrialization of the economy, which enshrined the raw materials industry specialization. Russia is far behind in terms of development of the manufacturing industry from the developed countries of the world community. Particularly clear the gap is observed in comparisons with such countries as China, Germany, Japan. Thus, Russia's share in global production volume of new machines and forging equipment is about $0.5 \%$. This is 52 times lower than in Germany and 69 times - than in Japan (Koroleva, 2010).

This economic policy is reflected in the social and labor potential in not the best way, because the highly skilled workers of high-tech sectors of the economy not only numerically reduced, but also appeared in a status of "cultural outcasts." Under the rule of rentiers we can see the prevailing the motivational model of work behavior like "maximum income with minimum labor effort," because by "honest work" it is impossible to ensure a decent standard of living possible. As a result, the concrete labor in the Russian society is undergoing a significant devaluation.

Most working people in our country are paid for their work that money that can hardly ensure the survival rate. And growing huge income differentiation in the Russian society is not due to the difference in the quality of human capital. In the absence of an equitable distribution of income in the Russian society, mismatch between the complexity of labor and the measure of its payment, the standard of living of the working person, both the 
value of a particular work and the motivation to work as a whole decrease. Workers of a new generation demonstrate the motivational attitude not only to the highly creative, interesting and meaningful work, but one that will provide a decent standard of living. ( Feigin,2006)

Therefore, we can say that there is a huge reserve to increase motivation for productive work in Russia in the first place by ensuring fairness in the evaluation of labor, and on this basis to increase the material interest; secondly, through the modernization of production, which allows you to automate routine work, qualitatively improve working conditions, increase competition jobs.

\section{Discussion}

Nowadays, the ratio of individual and public interests has become the focus of economic theory. Without defining it, it is impossible to understand and explain the complex contemporary reality. Methodological postulating of individualism as the main and almost the only essential characteristic of personality has long been unquestioned in economics. But gradually in human life the public interests have become increasingly important, and the many schools of economic theory could no longer ignore their presence. Disputes about it moved to a more specific plane - what constitutes the public interest, where they come from and how to relate to the original individual aspirations and preferences.

More and more scientists who specify the apparent one-sidedness of the methodological postulates of individualism, the impossibility of giving a scientific explanation of the existence of not only the individual, but also public goods only from one side, as well as the various functions of the modern state, these benefits are creating and providing for its citizens. So, R. Greenberg and A. Rubinstein, co-developing the concept of socio economic dynamics, in their books and articles on this subject emphasize that the theoretical core of this concept is based on the rejection of absolute methodological individualism and the transition to a softer principle of complementarity, admitting the existence of group interests along with the preferences of individuals, despite the fact that the first is not always possible to narrow down to the second.

Besides the Nobel Prize winner in Economics Kenneth Arrow has a similar opinion and believes that "a man is undoubtedly driven by motives that go beyond his own" I ". This is the sense of responsibility of the individual to public interests are also manifest in it, which are not reducible to individual motivation.

The Nobel Prize in Economics M. Allais has taken an attempt to connect social justice and economic efficiency. "The economic analysis allows us to conclude confidently - Alla wrote - that, under central planning there cannot be any state of maximum efficiency and only the process of empirical solutions in terms of the maximum efficiency of decentralized markets within the economy is able to lead to this condition. Therefore, in terms of human needs the collectivist economy could only be effective only if it had been organized on the basis of the economy markets, and any centralized and authoritarian planning only leads to significant losses in production and welfare... And that means that all the problems faced by the collectivist economies are substantially the same as the problems faced by the capitalist economy "(Allais, 1967). Thus, theoretically collectivist economy can achieve a sufficiently high efficiency. This requires, however, that the political authorities will reject the totalitarian claims and will satisfy with the most common tasks in the economic sphere: "It is erroneous the following statement ... that the collectivist economy in any case not be able to reach an optimal state because of the theoretical impossibility of its competitive... Such an organization is quite acceptable. However, it suggests that political power knows economics well and systematically and simultaneously limit its activities only to the general economic framework (planning structures). Assuming that the collectivist economy is really competitive, then it could probably provide better and faster economic conditions of maximum social efficiency than our capitalist society, even reformed" (Allais, 1947). However, the theoretical possibility of combining the collectivist ownership and the competition is unlikely to be practically implemented in the foreseeable future due to the excessive politicization of the existing society, and known for his naivety in economic matters: "Every realistically thinking person must admit that the actual implementation of a competitive organization by fully socialized economy would meet considerable difficulties, which can be, in all likelihood, be considered insurmountable under the current state of economic and political upbringing the people ". In another study, Alla notes that in a society based on collectivist property will not be democracy and political freedom: "Experience shows that private ownership is a prerequisite for the exercise of political freedoms. I state, in particular, that in history there is a very strong correlation between the extent of private property and the extent of freedoms. If there is no private property, there can be no political freedom. The converse is not true. There is not a single example of a politically democratic society without private property" (World Economy and International Relations, 1989). It is clear that Allais gives an individualistic sense to the concepts of democracy and political freedom, i.e. that meaning which they have in the developed capitalist countries. 
Pareto in his "Course of Political Economy" expressed the idea of the market socialist economy even before Allais. Allais as a passionate admirer of Pareto attempted to develop and elaborate the idea. In the opinion of Pareto, "if the socialist organization, whatever it may be, tends to society reaching a certain value in use, it only operates on the nature of the distribution and modifies it directly, giving things that it takes away from the ones to the others. With regard to production, it should be organized in the same way as under the regime of free competition and private ownership of capital "(Pareto, 1964). Pareto sprinkles sketch of the economic system with collective property, where the government regulates both the distribution and production, and shows that the effective organization of production involves conducting economic calculation based on the mechanism of exchange, i.e., the price system. Pricing consumer commodities somehow implies the market for these items. "Whatever the procedure of the existing distribution of goods established by the Government is, it is obvious that if it wishes to ensure that the ultimate use value to meet the needs of members of society, then it should make sure that everyone has exactly that good he is really needs. You cannot give glasses for the nearsighted to the farsighted and vice versa. It let them make exchange of goods distributed among them, if it makes a new distribution itself - the result is the same... If the exchange of commodities is allowed, then prices appear immediately again there; but if this new allocation is provided by the state itself, the prices only change its name because instead of their performance there will be those mechanisms which will implement the new system of distribution". Pricing in the sphere of the means of production, and in particular in capital may be performed by an exchange between the production units and administrative structures. As a result, the socialist economy will be based only on the exchange and the economic calculation and will not differ greatly in their effectiveness from the capitalist economy.

\section{Conclusion}

During the last 10-15 years the deviant worldviews of social organization have been clearly formed in relation to the native Russian, including the Soviet mentality, especially in the economic and legal fields. On the one hand, it might just be a consequence of the restructuring processes, if not for two things. Firstly, restructuring itself was largely the result of the preliminary deep changes in the ideological consciousness of the subject cultural creativity. And secondly, in the West, where there was no "perestroika" in the concrete historical sense of the word, there is growing a stronger paradoxical need to change the 180-degree the course of a conceptual approach to the principles of the construction of social and economic organization of society. And the interesting thing is that the opposite, polar relationship between the domestic and the Western intention justify economic programs, socio-legal and ideological orientations remained the same. Once the vector of the Russian progress in this aspect is now directed from the predominance of the collectivist paradigm to an increasing spread of individualistic schemes, while the West, on the contrary, more and more insistently welcomes dignity before so hostile collectivist position.

To understand and explain these paradoxes historical peculiarities of Russian and Western sense of justice means to see some fundamental processes of a modern cultural creativity in general, on a global scale.

Neither individualism nor collectivism can be exhaustively presented in the form given once and for all models of social development. Both of these paradigms are local, national or regional differences of their formation and functioning as well as its advantages and disadvantages. In addition, they both have evolved over time, experiencing the corrective influence not only the social reality in which they exist, but also spiritual context, typical for this time in this country and abroad. It is important to pay attention to those basic, inherent features of the "quality" of each paradigm with specific features that make its invariant nature, and that is why they are most vividly manifested in every historical case of individualism and collectivism as such.

In today's world the actual convergence of the mental attitudes of individualism and collectivism is due to the fact that each of their followers has now the opportunity, based on the historical experience of mankind, to make sure in both the limitations or, conversely, in undue absolute of one of them (for example, specific failures, imperfections, unexpected consequences, etc., in their implementation), and in particular benefits of the other conceptual scheme - at least in its theoretical promises, and often in some practical applications.

\section{References}

Allais, M. (1967). Les conditions de l'efficiacite dans l'economie (p. 104). (Centro Studi e Ricerche su Problemi Economico-Sociali) Milano.

Allais, M. (1947). Le problème de la planification économique dans une économie collectiviste Revue internationale des sciences sociales Kyklos, juillet et octobre 1947, vol. I, p. 254-280, et II, p. 48-71.

Allais, M. (1995). Economics as a science: Monograph. Science for Society, 1995 - 166 p: Ill. - (Modern 
Economic Thought).

Berdyaev N. A. (1990). The fate of Russia's experiments in psychology of war and ethnic. / Nikolai Berdyaev. Reprint edition reproduction 1918 - Moscow: Philosophical Society of the USSR, 1990 - 240 p. - B. c. LBC 87.3 (2) 61-63.

Churinov N. M. (2003). Perfection and freedom: Philosophical essays (2nd ed.). / NM Churinov. enlarged. Krasnoyarsk: [Siberian Institute of Business, Management and Psychology], 2003 - 515.

Grigorenko Okhotsimskii. Adequacy of the concept of social control of its culture and civilization: 09.00.11 Grigorenko, Dmitry E. Adequacy of the concept of social control of its culture and civilization (socio-philosophical analysis): Thesis. ... Candidate. Philosophy. Sciences: 09.00.11 Krasnoyarsk, 2006175 p. RSL OD, 61: 07-9 / 144

Eucken, W. (1996). The basis of the national economy (p. 351).

Feiguine G. (2004). Position in Perspektiven Russlands im Globalisierungsprozess. Monographie: Dissertation an der Deutschen Hochschule fuer Verwaltungswissenschaften Speyer. - Berlin: Logos- Verlag, 2004. - 14,5 п.л.

Feigin, G. F. (2006). Regional aspects of globalization and the prospects for relations between Russia and the European Union. Humanitarian problems of modern civilization. VI International Scientific Conference Likhachev Readings. May 26-27, 2006. - St. Petersburg.

Kulisher, I. M. (2004). The history of the Russian people (2nd ed., p. 743). Chelyabinsk Society.

Korolyova, E. I. (2010). Russia and countries of the world (p. 92). Retrieved from http://www.gks.ru/wps/wcm/connect/rosstat/rosstatsite/main/publishing/catalog/statisticCollections/doc_11 39821848594

Kozhevnikova, T. M. (2012). The nature of Russian collectivism. Socio-economic phenomena and processes.

Mamontov, V. D., \& Kozhevnikova, T. M. (2013). Cooperation in the past and at present time. Addressing social needs and the ratio of the objective reality of the economic and legal sciences. Published by IASHE. London.

Pareto, V. (1964). Cours d'economie politique. Paris, V 1, 1022.

Platonov, O. A. (2008). The economy of the Russian civilization.

Ritzer, G. (2002). Modern sociological theory (5th ed., Series "Masters of Psychology").

World Economy and International Relations. (1989). Russian Academy of Sciences, Institute of World Economy and International Relations. Moscow: Nauka.

\section{Copyrights}

Copyright for this article is retained by the author(s), with first publication rights granted to the journal.

This is an open-access article distributed under the terms and conditions of the Creative Commons Attribution license (http://creativecommons.org/licenses/by/3.0/). 